\title{
Durasi Membaca Buku merupakan Faktor Risiko Terjadinya Miopia pada Siswa Sekolah Dasar: Studi Perbandingan Rural dan Urban Area
}

\author{
Duration of Reading Books Is a Risk Factor for Occurring Myopia in Primary School Students: \\ Rural and Urban Area Comparative Studies
}

\author{
Wahju Ratna Martiningsih ${ }^{1}$, Fitria Devi ${ }^{2}$, Andra Novitasari ${ }^{1}$, Kanti Ratnaningrum ${ }^{1}$,* \\ ${ }^{1}$ Staf pengajar, Fakultas Kedokteran, Universitas Muhammadiyah Semarang, Indonesia \\ ${ }^{2}$ Mahasiswa, Fakultas Kedokteran, Universitas Muhammadiyah Semarang, Indonesia \\ *Penulis Korespondensi. Email: fitriadevi.unimus@gmail.com
}

Telp: +62-85741611224

\begin{abstract}
Abstrak
Latar Belakang: Kelainan refraksi merupakan salah satu penyebab ganggunan penglihatan. Miopia merupakan salah satu kelaian refraksi dan anak-anak merupakan kelompok yang menderita kelainan refraksi berupa miopia. Kebiasaan membaca merupakan salah satu faktor peneybab miopia. Penelitian ini bertujuan untuk mengetahui perbedaan faktor risiko penderita miopia pada anak Sekolah Dasar (SD) yang ada di urban area dan rural area

Metode: Penelitian observasional analitik dengan pendekatan cross sectional dengan teknik purposive sampling. Sampel merupakan siswa SD Negeri 03 Sidomukti (rural area) dan SD Hj. Isriati Baiturrahman 1 (urban area) kelas 4,5, dan 6. Kriteria eksklusi meliputi kelaianan konginetal mata, infeksi, atau pasca operasi intraokuler. Data penelitian menggunakan data primer berupa kuisioner dan pemeriksaan visus. Analisis menggunakan uji chi square.

Hasil: Dari 214 sampel terdiri dari 116 sampel rural area dan 98 sampel urban area, hanya faktor durasi membaca buku pada sampel di rural area yang berhubungan dengan terjadinya miopia $(\mathrm{p}=0,016)$, sedangkan faktor riwayat keluarga, konsumsi sayur atau buah, jarak baca, intensitas menonton TV, intensitas menggunakan komputer, intensitas menggunakan gadget, aktivitas luar ruangan hari sekolah, dan aktivitas luar ruangan hari libur tidak berhubungan dengan terjadinya miopia pada sampel rural maupun urban area.
\end{abstract}

Kesimpulan: Lama membaca buku berhubungan dengan terjadinya miopia pada rural area.

Kata Kunci: miopi, faktor risiko, rural, urban.

\begin{abstract}
Background: Refractive disorder is one of causes of visual impairment. Myopia is one of Refractive disorder and children as a group suffering from myopia, as refractive disorder. Reading habits are one of myopic predictor. This study aims to determine the differences of risk factors for myopia in elementary school student in rural areas and urban areas.

Method: Analytical observational study with cross sectional approach with purposive sampling technique. The sample is student of SD Negeri 03 Sidomukti (rural area) and SD Hj. Isriati Baiturrahman 1 (urban area) class 4.5, and 6. Exclusion criteria included congenital eye dysfunction, infection, or post intraocular surgery. The research data uses primary data from questionnaires and visual examination. Analysis using the chi square test.

Result: Through 214 samples consisting of 116 rural area samples and 98 urban area samples, only duration of textbook reading in the rural area was related to occurrence of myopia $(p=0.016)$, while family history, vegetable or fruit consumption, reading distance, intensity of watching TV, intensity of using computers, intensity of using gadgets, outdoor activities of school days, and outdoor activities on holidays are not related to occurrence of myopia in rural and urban areas.
\end{abstract}

Conclusion: Duration of textbook reading is related to occurrence of miopi in the rural area.

Keywords: myopia, risk factors, rural, urban. 


\section{PENDAHULUAN}

Kelainan refraksi merupakan salah satu penyebab ganggunan penglihatan. ${ }^{1}$ Miopia merupakan salah satu kelaian refraksi dan anak-anak merupakan kelompok yang menderita kelainan refraksi berupa miopia. ${ }^{2}$ Kebiasaan membaca merupakan salah satu faktor peneybab miopia., ${ }^{3,4}$ Penelitian ini bertujuan untuk mengetahui perbedaan faktor risiko penderita miopia pada anak Sekolah Dasar (SD) yang ada di urban area dan rural area.

\section{METODE}

Penelitian merupakan penelitian observasional analitik dengan pendekatan cross sectional, teknik penghitungan sampel menggunakan purposive sampling. Sampel merupakan siswa SD Negeri 03 Sidomukti (rural area) dan SD Hj. Isriati Baiturrahman 1 (urban area) kelas 4,5, dan 6. Kriteria eksklusi meliputi siswa yang telah menggunakan kacamata, kelaianan konginetal mata, infeksi, atau pasca operasi intraokuler.
Juni 2019

Data penelitian menggunakan data primer berupa kuisioner dan pemeriksaan visus. Data kuisioner meliputi durasi membaca buku, riwayat keluarga, konsumsi sayur atau buah, jarak membaca buku, intensitas menonton TV, intensitas menggunakan komputer, intensitas menggunakan gadget, aktivitas luar ruangan hari sekolah, dan aktivitas luar ruangan hari libur. Pemeriksaan visus dilakuakn oleh dokter spesialis mata menggunakan optotik snellen Analisis menggunakan uji chi square. Peelitian sudah mendapat persetujuan etik dengan diterbitkannya keteragan kelaikan etik no.008/EC/FK/2019.

\section{HASIL}

Dari 214 sampel yang diikutkan penelitian, terdiri dari 116 sampel rural area dan 98 sampel urban area. Sebagian besar sampel berjenis kelamin laki-laki baik pada rural area $(53,3 \%)$ maupun pada urban area $(51,0 \%)$. Kelaianan refraksi, miopia paling banyak ditemukan pada sampel urban area sebesar 55 orang $(56,1 \%)$ (tabel 1$)$.

Tabel 1. Karkteristik Sampel

\begin{tabular}{ccccc}
\hline \multirow{2}{*}{ Variabel } & \multicolumn{2}{c}{ Urban area } & \multicolumn{2}{c}{ Rural area } \\
\cline { 2 - 5 } & $\mathrm{N}(98)$ & $\%$ & $\mathrm{~N}(116)$ & $\%$ \\
\hline Jenis kelamin & & & & \\
Laki-laki & 50 & 51,0 & 65 & 53,3 \\
Perempuan & 48 & 49,0 & 51 & 41,8 \\
Miopia & & & & \\
Tidak & 43 & 43,9 & 107 & 92,2 \\
Ya & 55 & 56,1 & 9 & 7,8 \\
\hline
\end{tabular}

Dari tabel 2, diapatkan hasil hanya faktor durasi membaca buku yang berhubungan dengan terjadinya miopia $(\mathrm{p}=0,016)$ pada rural area, sedangkan faktor riwayat keluarga, konsumsi sayur atau buah, jarak baca, intensitas menonton TV, intensitas menggunakan komputer, intensitas menggunakan gadget, aktivitas luar ruangan hari sekolah, dan aktivitas luar ruangan hari libur tidak berhubungan dengan terjadinya myopia pada rural area dengan masingmasing $\mathrm{p}$-value pada faktor riwayat keluarga $\mathrm{p}=1,000$; konsumsi sayur atau buah $\mathrm{p}=0,210$; jarak baca $\mathrm{p}=1,000$; intensitas menonton $\mathrm{TV}$ $\mathrm{p}=0,144$; intensitas menggunakan komputer $\mathrm{p}=0,499$; intensitas menggunakan gadget $\mathrm{p}=0,371$; aktivitas luar ruangan hari sekolah $\mathrm{p}=0,092$; dan aktivitas luar ruangan hari libur sebesar $\mathrm{p}=0,092$.

Dari tabel 3. di dapatkan hasil tidak ada faktor risiko yang berhubungan dengan teradinya miopia pada urban area. Adapun faktor-faktor tersebut meliputi riwayat keluarga $(p=0,090$, konsumsi sayur atau buah 
( $\mathrm{p}=0,611)$, durasi membaca buku $(\mathrm{p}=0,908)$, jarak baca $(\mathrm{p}=0,785)$, intensitas menonton $\mathrm{TV}$ $(\mathrm{p}=0,265)$, intensitas menggunakan komputer $(\mathrm{p}=0,439)$, intensitas menggunakan gadget $(\mathrm{p}=0,136)$, aktivitas luar ruangan hari sekolah $(\mathrm{p}=0,700)$ dan aktivitas luar ruangan hari libur $(\mathrm{p}=0,400)$.

Tabel 2. Hubungan faktor risiko dengan terjadinya myopia pada rural area

\begin{tabular}{|c|c|c|c|}
\hline \multirow{2}{*}{ Faktor risiko } & \multicolumn{2}{|c|}{ Miopi } & \multirow{2}{*}{ P-value } \\
\hline & $\mathrm{N}(116)$ & $\%$ & \\
\hline \multicolumn{4}{|l|}{ Riwayat keluarga menderita miopi } \\
\hline Tidak & 94 & 81,0 & \multirow[t]{2}{*}{1,000} \\
\hline Ya & 22 & 19,0 & \\
\hline \multicolumn{4}{|l|}{ Konsumsi sayur atau buah dalam sehari } \\
\hline Baik (2x) & 89 & 76,7 & \multirow[t]{2}{*}{0,210} \\
\hline Kurang $(<2 \mathrm{x})$ & 27 & 23,3 & \\
\hline \multicolumn{4}{|l|}{ Durasi membaca buku } \\
\hline Baik $(<2$ jam $)$ & 97 & 83,6 & \multirow{3}{*}{0,016} \\
\hline Kurang baik (2-3 jam) & 17 & 14,7 & \\
\hline Tidak baik (>3 jam) & 2 & 1,7 & \\
\hline \multicolumn{4}{|l|}{ Jarak baca } \\
\hline Cukup $(30 \mathrm{~cm})$ & 97 & 83,6 & \multirow[t]{2}{*}{1,000} \\
\hline Dekat $(<30 \mathrm{~cm})$ & 19 & 16,4 & \\
\hline \multicolumn{4}{|l|}{ Intensitas menonton TV dalam sehari } \\
\hline Rendah $(<2$ jam $)$ & 59 & 50,9 & \multirow{3}{*}{0,144} \\
\hline Sedang (2-4 jam) & 54 & 46,6 & \\
\hline Tinggi (>4 jam) & 3 & 2,6 & \\
\hline \multicolumn{4}{|c|}{ Intensitas menggunakan komputer dalam sehari } \\
\hline Tidak pernah & 79 & 68,1 & \multirow{3}{*}{0,499} \\
\hline Rendah (1-3 jam) & 32 & 27,6 & \\
\hline Sedang (4-8 jam) & 5 & 4,3 & \\
\hline \multicolumn{4}{|c|}{ Intensitas penggunaan gadget dalam sehari } \\
\hline Tidak pernah & 17 & 14,7 & \multirow{3}{*}{0,371} \\
\hline Rendah (1-3 jam) & 81 & 69,8 & \\
\hline Sedang (4-8 jam) & 18 & 15,5 & \\
\hline \multicolumn{4}{|l|}{ Aktivitas luar ruangan hari sekolah } \\
\hline Baik $(\geq 1 \mathrm{x})$ & 109 & 94,0 & \multirow[t]{2}{*}{0,092} \\
\hline Kurang $(<1 \mathrm{x})$ & 7 & 6,0 & \\
\hline \multicolumn{4}{|l|}{ Aktivitas luar ruangan hari libur } \\
\hline Baik $(\geq 1 x)$ & 109 & 94,0 & \multirow[t]{2}{*}{0,092} \\
\hline Kurang $(<1 \mathrm{x})$ & 7 & 6,0 & \\
\hline
\end{tabular}

\section{PEMBAHASAN}

Penelitian ini menunjukan bahwa tidak ada faktor risiko yang berpengaruh terhadap terjadinya miopia pada urban area. sedangkan pada rural area, durasi membaca buku adalah satu-satunya faktor risiko yang berpengaruh terhadap kejadian miopia. Hal ini sesuai dengan penelitian sebelumnya yang menyatakan bahwa membaca dalam waktu yang lama dapat mempengaruhi kejadian 
myopia. Aktifitas jarak dekat seperti membaca buku yang dilakukan secara terus menerus setiap hari dalam jangka waktu yang lama, lebih dari 2 jam setiap hari dapat meyebabkan terjadinya miopia. ${ }^{5}$

Tabel 3. Tabel hubungan faktor risiko dengan terjadinya myopia pada urban area

\begin{tabular}{|c|c|c|c|}
\hline \multirow{2}{*}{ Faktor risiko } & \multicolumn{2}{|c|}{ Miopi } & \multirow{2}{*}{ P-value } \\
\hline & $\mathrm{N}(98)$ & $\%$ & \\
\hline \multicolumn{4}{|l|}{ Riwayat keluarga menderita miopi } \\
\hline Tidak & 43 & 43,9 & \multirow[t]{2}{*}{0,090} \\
\hline Ya & 55 & 56,1 & \\
\hline \multicolumn{4}{|l|}{ Konsumsi sayur atau buah dalam sehari } \\
\hline Baik $(2 \mathrm{x})$ & 62 & 63,3 & \multirow[t]{2}{*}{0,611} \\
\hline Kurang $(<2 \mathrm{x})$ & 36 & 36,7 & \\
\hline \multicolumn{4}{|l|}{ Durasi membaca buku } \\
\hline Baik (<2jam) & 60 & 61,2 & \multirow{3}{*}{0,908} \\
\hline Kurang baik (2-3jam) & 34 & 34,7 & \\
\hline Tidak baik (>3jam) & 4 & 4,1 & \\
\hline \multicolumn{4}{|l|}{ Jarak baca } \\
\hline Cukup (30cm) & 63 & 64,3 & \multirow[t]{2}{*}{0,785} \\
\hline Dekat $(<30 \mathrm{~cm})$ & 35 & 35,7 & \\
\hline \multicolumn{4}{|l|}{ Intensitas menonton TV dalam sehari } \\
\hline Rendah $(<2$ jam $)$ & 53 & 54,1 & \multirow{3}{*}{0,265} \\
\hline Sedang (2-4 jam) & 39 & 39,8 & \\
\hline Tinggi (>4 jam) & 6 & 6,1 & \\
\hline \multicolumn{4}{|c|}{ Intensitas menggunakan komputer dalam sehari } \\
\hline Rendah (1-3 jam) & 91 & 92,9 & \multirow{3}{*}{0,439} \\
\hline Sedang (4-8 jam) & 5 & 5,1 & \\
\hline Berat $(9-16$ jam $)$ & 2 & 2,0 & \\
\hline \multicolumn{4}{|c|}{ Intensitas penggunaan gadget dalam sehari } \\
\hline Rendah (1-3 jam) & 68 & 69,4 & \multirow{3}{*}{0,136} \\
\hline Sedang (4-8 jam) & 27 & 27,6 & \\
\hline Berat $(9-16$ jam $)$ & 3 & 3,1 & \\
\hline \multicolumn{4}{|l|}{ Aktivitas luar ruangan hari sekolah } \\
\hline Baik ( $\geq 1 \mathrm{x})$ & 71 & 72,4 & \multirow[t]{2}{*}{0,700} \\
\hline Kurang $(<1 \mathrm{x})$ & 27 & 27,6 & \\
\hline \multicolumn{4}{|l|}{ Aktivitas luar ruangan hari libur } \\
\hline $\operatorname{Baik}(\geq 1 \mathrm{x})$ & 71 & 72,4 & \multirow[t]{2}{*}{0,400} \\
\hline Kurang $(<1 \mathrm{x})$ & 27 & 27,6 & \\
\hline
\end{tabular}

Riwayat keluarga menderita miopi tidak berhubungan dengan terjadinya miopia pada anak SD di urban maupun di rural area. Hasil ini berbeda dengan penelitian terdahulu yang menyatakan bahwa sebagian besar siswa yang menderita miopia memiliki orang tua yang juga menderita miopia. 5,6
Konsumsi sayur atau buah tidak berhubungan dengan terjadinya miopia anak SD di urban maupun di rural area. Hal ini dimungkinkan karena banyak anak yang tidak menyukai sayur dan lebih memilih makanan yang cepat saji. Selain itu zat gizi anti miopia tidak hanya terkandung dalam sayur dan buah 
tetapi juga terdapat pada bahan makanan lain seperti vitamin A, vitamin A tidak hanya didapatkan dari sayur dan buah namun juga dapat diperoleh dari kuning telur, hati, susu, dan mentega. ${ }^{7}$

Jarak membaca buku tidak berhubungan dengan kejadian miopi anak SD di urban maupun di rural area. Pernyataan ini tidak sesuai dengan penelitian sebelumnya yang menyatakan bahwa melakukan aktifitas pada jarak dekat $<30 \mathrm{~cm}$ memicu terjadinya miopi. ${ }^{8}$ kemungkinan hal ini terjadi karena penghitungan jarak baca kurang presisi karena penghitungan tidak menggunakan alat ukur seperti penggaris dan sampel hanya mengiraira jarak baca yang biasa dilakukan

Intensitas menonton TV tidak berhubungan dengan terjadinya miopia baik anak SD di urban area maupun di rural area. Pernyataan ini tidak sesuai dengan pernyataan sebelumnya yang menyatakan bahwa jarak, durasi dan lingkungan menonton televisi mungkin bertanggung jawab untuk mengganggu perkembangan visual anak. ${ }^{9}$

Intensitas menggunakan komputer atau gadget dalam sehari tidak berhubungan dengan terjadinya miopia pada anak SD di urban area maupun di rural area. Pernyataan tidak sesuai dengan penelitian sebelumnya yang menyatakan bahwa menggunakan komputer dengan intensitas tinggi ( $>4$ jam) dalam sehari selama satu tahun dapat berpengaruh terhadap derajat miopia. ${ }^{9,10}$ Posisi duduk di depan komputer dalam jangka waktu lama, memperberat kerja otot mata dalam pengaturan fokus dan menimbulkan ketegangan mata. Sinar biru pada computer bersifat miopigenik, sehingga meningkatkan risiko menderita miopia. ${ }^{5}$

Hasil penelitian ini menunjukkan bahwa aktivitas di luar ruangan tidak berpengaruh terhadap terjadinya miopia. Pernyataan ini tidak sesuai dengan penelitian terdahulu yang menyatakan kurangnya aktivitas di luar ruangan merupakan salah satu faktor risiko terjadinya miopi. ${ }^{11}$ Aktivitas luar ruang merupakan faktor protektif yang bersifat meningkatkan depth of focus dan kejernihan retina. Hal ini yang menyebabkan konstriksi pupil akibat tingginya intensitas cahaya dan berkurangnya permintaan melihat jarak dekat sehingga menurunkan risiko miopia. $^{12}$

\section{KESIMPULAN}

Lama membaca buku berhubungan dengan terjadinya miopia pada rural area. Perlu dilakukan penelitian serupa dengan metode wawancara kuisioner secara langsung untuk menghindari bias data penelitian.

\section{DAFTAR PUSTAKA}

1. Depkes RI. Katarak Penyebab Utama Kebutaan di Indonesia [Internet]. 2017. Available from: http://www.depkes.go.id/article/view/17 100400003/katarak-penyebab-utamakebutaan-di-indonesia.html

2. Sun JT, An M, Yan XB, Li GH, Wang DB. Prevalence and Related Factors for Myopia in School-Aged Children in Qingdao. J Ophthalmol. 2018;2018.

3. Gwiazda JE, Hyman L, Norton TT, Hussein MEM, Marsh-Tootle W, Manny R, et al. Accommodation and related risk factors associated with myopia progression and their interaction with treatment in COMET children. Investig Ophthalmol Vis Sci [Internet]. 2004;45(7):2143-51. Available from: https://www.ncbi.nlm.nih.gov/pubmed/1 5223788

4. Xiong S, Sankaridurg P, Naduvilath T, Zang J, Zou H, Zhu J, et al. Time spent in outdoor activities in relation to myopia prevention and control: a metaanalysis and systematic review. Acta Ophthalmol [Internet]. 2017;95(6):55166. Available from: https://www.ncbi.nlm.nih.gov/pmc/articl es/PMC5599950/

5. Komariah C, A NW. Hubungan Status Refraksi, dengan Kebiasaan Membaca, Aktivitas di Depan Komputer, dan 
Status Refraksi Orang Tua pada Anak Usia Sekolah Dasar. J Kedokt Brawijaya [Internet]. 2014;28. Available from: http://jkb.ub.ac.id/index.php/jkb/article/ view/443

6. Goldschmidt E, Jacobsen N. Genetic and environmental effects on myopia development and progression. Eye [Internet]. Nature Publishing Group; 2014;28(2):126-33. Available from: http://dx.doi.org/10.1038/eye.2013.254

7. S A. Prinsip Dasar Ilmu Gizi. Jakarta: Gramedia Pustaka Utama; 2001.

8. Ip JM, Saw SM, Rose KA, Morgan IG, Kifley A, Wang JJ, et al. Role of near work in myopia: Findings in a sample of Australian school children. Investig Ophthalmol Vis Sci [Internet]. 2008;49(7):2903-10. Available from: https://www.ncbi.nlm.nih.gov/pubmed/1 8579757

9. Seema $\mathrm{S}, \mathrm{Bm} \mathrm{V}, \mathrm{Ak} \mathrm{K}$, Minakshi $\mathrm{K}$, Manish G. Children In Rural Haryana . 2011;2(1):1-5. Available from: https://print.ispub.com/api/0/ispubarticle/10710

10. Hanum IF. Efektivitas Penggunaan Screen Pada Monitor Pekerja Call Centre di PT INDOSAT NSR. 2008;

11. Dirani M, Tong L, Gazzard G, Zhang X, Chia A, Young TL, et al. Outdoor activity and myopia in Singapore teenage children. $\mathrm{Br} \quad \mathrm{J}$ Ophthalmol [Internet]. 2009;93(8):997-1000. Available from: https://www.ncbi.nlm.nih.gov/pubmed/1 9211608

12. Ramamurthy D, Lin Chua SY, Saw SM. A review of environmental risk factors for myopia during early life, childhood and adolescence. Clin Exp Optom [Internet]. 2015;98(6):497-506. Available from: http://doi.wiley.com/10.1111/cxo.12346 